\title{
A novel approach to meet the unmet need for family planning
}

\author{
Subrata Samanta ${ }^{1 *}$, Sujoy Dutta ${ }^{2}$, Sudipta Samanta $^{3}$, Agrima Mullick $^{3}$
}

\begin{abstract}
${ }^{1}$ Department of Obstetrics and Gynecology, Rampurhat Government Medical College, Rampurhat, West Bengal, India ${ }^{2}$ Department of Obstetrics and Gynecology, ESI PGIMSR, Esic Medical College and Esic Hospital and ODC (EZ), Joka, West Bengal, India

${ }^{3}$ Department of Obstetrics and Gynecology, R. G. Kar Medical College and Hospital, Kolkata, West Bengal, India
\end{abstract}

Received: 21 October 2018

Accepted: 13 November 2018

\author{
*Correspondence: \\ Dr. Subrata Samanta, \\ E-mail: drsubratasamanta@gmail.com
}

Copyright: $\odot$ the author(s), publisher and licensee Medip Academy. This is an open-access article distributed under the terms of the Creative Commons Attribution Non-Commercial License, which permits unrestricted non-commercial use, distribution, and reproduction in any medium, provided the original work is properly cited.

\begin{abstract}
Background: Post-partum intra-uterine contraceptive device is one of the important methods of spacing to meet up the unmet need of family planning. The low complication rate, ease and certainty of insertion and one-time adoption advantages made it an option of family planning by Government of India. In the background of recent trends in family planning, the study aims to establish the efficacy and draw-backs of PP-IUCD among the clients in a tertiary care hospital of West Bengal.

Methods: Prospective observational study on 1680 women during January 2016 to December 2016, where the PPIUCD was given to the patients after vaginal delivery or Cesarean section and were followed up to 3 months.

Results: During the study $1.37 \%$ patients did not turnup in either follow-up. The most common complication encountered was missing thread (4.64\% at 6th week follow-up and $6.67 \%$ at 3 rd month follow-up). Expulsion rate was much lower (2.02\% at 6th week and $2.5 \%$ at 3 rd month). Heavy bleeding per-vagina was in $1.55 \%$ at 6 th week and $2.08 \%$ at 3rd month. Pain abdomen was $.83 \%$ at 6 th week and $1.67 \%$ at 3rd month. Incidence of perforation and failure was both nil at either follow-up. Dysmenorrhea was complained $2.44 \%$ at 6th week and 3.33\% at 3rd month. Overall satisfaction rate at 6th week $(86.05 \%)$ was higher than non-satisfaction $(13.95 \%)$. This was also true for 3rd month where satisfaction rate $(77.85 \%)$ was higher than non-satisfaction rate $(22.15 \%)$.

Conclusions: PP-IUCD appears to be a safe, efficacious, acceptable and accessible method of contraception.
\end{abstract}

Keywords: Cesarean section, Dysmenorrhea, Intrauterine contraceptive device, Perforation, PID, Vaginal delivery

\section{INTRODUCTION}

Intrauterine Contraceptive Device (IUCD) refers to a temporary method of contraception where a device is introduced in the uterine cavity inciting biochemical, histological and inflammatory changes in the endometrium, altering tubal motility and interfering with sperm transport and prevent fertilisation. ${ }^{1}$ Some designs contain Copper $(\mathrm{Cu})$ which interferes with blastocyst implantation whereas some contains hormones e.g. progesterone contributing additional mechanisms to contraception, overall, provides benefits by having a low failure rate (0.1-2 Hundreds of Women Years (HWY)). ${ }^{1}$ Total unmet need for family planning refers to unmet need for both spacing and limiting where unmet need for spacing refers to fecund women, neither pregnant nor amenorrhoeic, who are not using any method of contraception but want to wait two or more years for their next childbirth or are unsure about another child or are desirous of child but are unsure about when to have it. ${ }^{2}$ According to District Level Health Survey-3 (DLHS-3), in 2007-2008, the unmet need for spacing was total 5.3\%, $5.7 \%$ in rural and $4.3 \%$ in urban region. ${ }^{2}$ The immediate objective of National Population Policy 2000 (NPP-2000) 
was to address the unmet need for contraception, healthcare infrastructure and to provide basic reproductive and child health care. ${ }^{3}$

During that time, there was estimated $20 \%$ unmet need for contraception which required urgent steps to make wide availability of contraceptives especially in rural areas where $74 \%$ population lived. ${ }^{4}$ In resource-constraint countries like India, IUCD provides excellent means of contraception since this ensures certainty and ease of insertion, easy to follow-up, one-time adoption advantages and less complications.

One of the strategies adopted with IUCD is inserting in Post-Partum period (PP-IUCD) considering that $65 \%$ of women in first year post-partum have unmet need for family planning. ${ }^{5}$ This strategy was facilitated as there has been increase in institutional delivery rate.

According to DLHS-3, institutional delivery rate in 2007 2008 was total $47 \%, 37.8 \%$ in rural and $70.5 \%$ in urban area. $^{2}$ PP-IUCD confers multiple advantages like certainty of insertion, reduced perception of initial side effects, requirement of minimal additional equipment and overall, is a time-saving procedure giving mother an efficient spacing method before discharge without interfering breastfeeding. ${ }^{5}$

Timing of PP-IUCD can be post-placental (within 10 minutes after delivery of placenta following a vaginal delivery), Intra-cesarean (after removal of placenta, before wound closure, immediately following cesarean section), immediate post-partum (within $48 \mathrm{hrs}$ after delivery); however, IUCD cannot be inserted within 48 hrs to 6 weeks post-partum. ${ }^{5}$

A comparative evaluation of PP-IUCD vs interval IUCD in a prospective observational study showed PP-IUCD has low rate of perforation (probably because of thick uterine wall), no increased risk of endometritis, bleeding, no interference with involution of uterus. ${ }^{6}$ As per National Health Mission (NHM) Cu-T 380A and Multiload-375 are recommended for IUCD which could be inserted by nursing stuffs and doctors. ${ }^{7}$ The following study aims to establish the efficacy and possible complications of PP-IUCD insertion in a tertiary care hospital of West Bengal.

\section{METHODS}

This study was conducted in the department of Obstetrics and Gynecology, R. G. Kar Medical College and Hospital between January 2016 to December 2016. The Study was based on the population where all women fitting the inclusion and exclusion criteria in the first 6 months were counselled in antenatal clinic, labour room and were encouraged to opt for post-partum IUCD insertion. Study design was based on prospective observational study, there was total 1680 women was enrolled.

\section{Inclusion criteria}

- Woman who had given informed consent for postpartum IUCD insertion

- Women who did not have any contraindications as mentioned in the exclusion criteria.

\section{Exclusion criteria}

- $\quad$ Past history of $(\mathrm{h} / \mathrm{O})$ ectopic pregnancy

- Hemorrhagic disorder

- Known case of heart disease, diabetes

- Uterine anomaly causing distortion of uterine cavity

- Chorioamnionitis or ruptured membrane for more than 18 hours

- $\mathrm{Hb}<8 \mathrm{~g} \%$, unresolved PPH

- H/o multiple sexual partners

- Past or current genital tract infection

- Potential infected case of dai handling.

Study variable

- Rate of follow-up at $6^{\text {th }}$ week and $3^{\text {rd }}$ month.

- Different complications following PP-IUCD

Study tools

- Government approved IUCD (Cu-T 380A and Multiload-375).

- $\quad$ Proper equipment for inserting IUCD.

- Clinical history and detailed examination in antenatal period.

- USG of pelvis.

In the study group, women who had normal vaginal delivery, post-placental IUCD was inserted within 10 minutes of expulsion of placenta using Kelly's forceps (12-inch stainless steel, serrated curved forceps), taking all aseptic precautions. In case of cesarean section, postplacental IUCD was placed through the lower uterine segment with the help of Ring forceps. IUCD thread was not pushed into the cervical canal. Care was taken not to include the thread in the suture line. Uterine incision was routinely closed. During the postpartum period, the women were given a post-placental IUCD information leaflet and explained about the follow up at 6 weeks, 3 months or as soon as they notice any warning signs such as:

- Foul smelling lochia

- Excessive bleeding per vagina

- Any signs and symptoms of infection like- fever, myalgia, body ache, discharge per-vagina, lower abdominal pain

- Expulsion of IUCD.

During the follow up, detailed history including the menstrual cycle and regarding the warning signs was 
taken. Physical and pelvic examinations were carried out. Post-placental IUCD thread was checked and was trimmed. In case the IUCD thread was not found on per speculum examination, USG was done to confirm the presence of IUCD and the patient was counselled. Women were enquired about their satisfaction level.

\section{Statistical analysis}

Statistical analysis was done after the collected data was tabulated in a MS Excel Spreadsheet and then calculations were done.

\section{RESULTS}

\section{Rate of follow-up at $6^{\text {th }}$ week and $3^{\text {rd }}$ month}

There were 23 patients at the end of the study who never came for follow-up. Thus, loss to follow-up was $1.37 \%$. However, the rate of follow-up at $6^{\text {th }}$ week and at $3^{\text {rd }}$ month was comparable.

Table 1: Distribution of patients according to followup.

\begin{tabular}{|l|l|l|}
\hline $\begin{array}{l}\text { Follow-up } \\
\text { schedule }\end{array}$ & $\begin{array}{l}\text { Number of } \\
\text { patients }\end{array}$ & $\%$ of total \\
\hline At $6{ }^{\text {th }}$ week & 1634 & 97.26 \\
\hline At $3^{\text {rd. }}$ Month & 1657 & 98.63 \\
\hline No follow-up at all & 23 & 1.37 \\
\hline
\end{tabular}

\section{Complications at $6^{\text {th }}$ week}

Most patients complained of missing thread. Perforation and failure were nil. Expulsion, Heavy bleeding, Dysmenorrhea, Vaginal discharge were other complications.

Table 2: Distribution of patients according to different complications at $6^{\text {th }}$ week.

\begin{tabular}{|l|l|l|}
\hline Complications & No. of patients & $\%$ of total \\
\hline Missing thread & 78 & 4.64 \\
\hline Expulsion & 34 & 2.02 \\
\hline Heavy bleeding per-vagina & 26 & 1.55 \\
\hline Dysmenorrhea & 41 & 2.44 \\
\hline PID & 12 & 0.71 \\
\hline Perforation & 0 & 0.00 \\
\hline Discontinuation & 11 & 0.65 \\
\hline Pain abdomen & 14 & 0.83 \\
\hline Vaginal discharge & 26 & 1.55 \\
\hline Failure & 0 & 0.00 \\
\hline
\end{tabular}

\section{Complications at $3^{\text {rd }}$ month}

Missing thread was the commonest complication. Perforation and failure were nil. Expulsion, dysmenorrhea, heavy bleeding, vaginal discharge was other common complaint.
Table 3: distribution of patients according to different complications at $3^{\text {rd }}$ month.

\begin{tabular}{|c|c|c|}
\hline Complications & $\begin{array}{l}\text { No. of } \\
\text { patients }\end{array}$ & $\%$ of total \\
\hline Missing thread & 112 & 6.67 \\
\hline Expulsion & 42 & 2.50 \\
\hline $\begin{array}{l}\text { Heavy bleeding per- } \\
\text { vagina }\end{array}$ & 35 & 2.08 \\
\hline Dysmenorrhea & 56 & 3.33 \\
\hline PID & 17 & 1.01 \\
\hline Perforation & 0 & 0.00 \\
\hline Discontinuation & 23 & 1.37 \\
\hline Pain abdomen & 28 & 1.67 \\
\hline Vaginal discharge & 54 & 3.21 \\
\hline Failure & 0 & 0.00 \\
\hline
\end{tabular}

\section{Distribution of patients according to their satisfaction}

Both during $6^{\text {th }}$ week and $3^{\text {rd }}$ month the $\%$ of patients who were satisfied were significantly more than that of those who were not satisfied.

Table 4: Distribution of patients according to their level of satisfaction.

\begin{tabular}{|l|l|l|}
\hline $\begin{array}{l}\text { Timing of } \\
\text { follow-up }\end{array}$ & $\begin{array}{l}\text { Satisfied (\% of } \\
\text { total) }\end{array}$ & $\begin{array}{l}\text { Not satisfied } \\
\text { (\% of total) }\end{array}$ \\
\hline At $6{ }^{\text {th }}$ week & 86.05 & 13.95 \\
\hline At $3^{\text {rd }}$ month & 77.85 & 22.15 \\
\hline
\end{tabular}

\section{DISCUSSION}

In present study from Table 2 and table 3, we can see that missing thread was the commonest complication. This goes against the findings provided in the study by Mishra $\mathrm{S}$, where the author showed bleeding $(23.5 \%)$ was the commonest complication. ${ }^{8}$ In their study, missing thread was encountered only in $8.69 \%$ patients at 4-6 weeks follow-up. Similar findings were reported by another study by Kant $\mathrm{S}$ et al, where they found bleeding (5.5\%) was more common complication than missing thread $(2.3 \%) .{ }^{9}$ However, in another study by Garg $\mathrm{N}$ et al, showed that incidence of missing thread was more in case of Multiload $375(25.77 \%)$ than Cu-T 380A (10-36\%). ${ }^{10}$ They also showed that bleeding (less than 11.3\%) was less than incidence of missing thread in case of multiload 375. The possible explanation of this can be the initial length of string in both designs are different. This explanation has also been provided in a study. ${ }^{11}$ In the same study, the incidence of missing thread was shown more in case of intra-cesarean insertion than postplacental insertion. ${ }^{11}$ In present study we used both CuT380A and multiload 375 and that could be resulted in more incidence of missing thread. If a specific instrument and technique directed approach had been taken during the study, the issue could be resolved. 
Another possible explanation can be coiling of the thread in the cervical canal. A study by Mishra S, showed that curled string was the most prevalent cause of missing thread $(52.63 \%$ of all missing threads were due to curled string). ${ }^{11}$ This is also supported by different literatures..$^{1,5}$

Expulsion was another complication which was comparatively prevalent in our study. The rate of expulsion in our study was much lower than that shown by other similar studies. ${ }^{8-12}$ This may be because of the timing of insertion, ideally which is within 10 minutes. If a technique directed approach was taken during the study, the question of disparity could be answered.

Menstrual abnormalities in form of Heavy Menstrual Bleeding (HMB) or menorrhagia was, as discussed above, much less prevalent in present study. Other menstrual abnormalities we encountered was dysmenorrhea. Dysmenorrhea is not that much commonly reported in other studies.

Rate of infection in our study was lower than the study conducted by Kumar S et al where they showed $5 \%$ rate of infections. ${ }^{13}$ However, in a study conducted in Paraguay, the rate of infection $(0.1 \%)$ was much lower than present study. ${ }^{14}$ It may be because that the incidences of PID was recorded on a patient-report basis. If microbiological confirmation along with detailed investigations with a proper follow-up had been done, the incidence may have fallen to comparable limits.

Pain abdomen was also an important consideration in different studies evaluating the efficacy of PP-IUCD. The incidence of pain abdomen was however, much less in our study compared to other studies. ${ }^{8,9,11}$ In different studies pain abdomen was also important issue in patients opting for IUCD removal. ${ }^{8,9,11}$

Loss to follow-up was also important consideration in our study. This appears to be a common problem since different literatures also faced the issue. Possible explanations are low educational level, lower socioeconomic level, less means of transport. In resourceconstraint countries many women play a significant role in their family income as a daily wage-earner. This is also an important and justified reason for the loss of followup. The incidence of loss to follow-up in our study $(1.37 \%)$ was very much lower than that reported by the study conducted by Garg N et al $(22.68 \%) .{ }^{10}$ Study by Nayak et al and Verma A et al, reported much higher rates of loss of follow-up (58\% and $40 \%$ respectively) Kittur et al, also reported similar higher rates of loss of follow-up. ${ }^{15,16}$ The reason of low loss of follow-up rate in our study is because of the fact that it was done by a more accessible tertiary care hospital situated in a wellcommunicated location. ${ }^{17}$ In this regard another questionnaire-based observational analysis could have been conducted in the study subjects which could have revealed their level of awareness, knowledge, and opinion about PP-IUCD insertion.
The rate of perforation in PP-IUCD is said to be lesser than that of interval IUCD insertion and is explained by the thickened post-partum uterine wall. ${ }^{6}$ Consecutively, in our study we did not encounter any case of perforation in either follow-up. In the study of Mishra S., the reported incidence of perforation was $0.14 \%$ and that presented with missing string contributing only $0.48 \%$ among all the missing string cases. ${ }^{11}$ Least incidence of perforation in PP-IUCD compared to interval IUCD is one of the reasons for its superiority. In present study failure was not encountered. The incidence is comparable to literature $(1.91 \%) .{ }^{11}$ The data presented in the study could have been more accurate if the study subjects would have been more, the follow-up was prolonged further. In the study Mishra S, they followed up their subjects for 3 years. ${ }^{11}$ A long-term follow-up was necessary to reveal the possible discrepancies in the comparison of results of our study with other studies.

The acceptability of PP-IUCD as a method of spacing is well-versed in literatures. Kant $\mathrm{S}$ et al, showed $38 \%$ acceptance rate amongst the Hindus and almost double acceptance rate in Muslims. ${ }^{9}$ Mishra S showed $20.73 \%$ acceptance rate in primigravida clients and $13.76 \%$ in multiparous clients. ${ }^{8}$ Though our study didn't consider acceptance rate as a parameter, but the satisfaction rate during either follow-up was significantly more than that of non-satisfied clients. Satisfaction rate in this regard can be taken as an indirect parameter for acceptance.

\section{CONCLUSION}

Finally, we can conclude that PP-IUCD is a safe, accessible, acceptable method of spacing to meet the unmet need of family planning with least complications.

\section{ACKNOWLEDGMENTS}

Authors would like to thank Principal of R. G. Kar Medical College, Head of the Department of Gynecology and Obstetrics, Prof. Dr. Nilanjana Chowdhury, Dr. Tulika Jha, Dr. Chhandos Saha and other colleagues, PGTs, interns, house stuffs and finally the patients who undertook this study.

\section{Funding: No funding sources Conflict of interest: None declared Ethical approval: Not required}

\section{REFERENCES}

1. Dutta DC. Contraception. In: Konar H, ed. DC Dutta's Textbook of Gynecology. $7^{\text {th }}$ ed. New Delhi. Jaypee Brothers Medical Publishers (P) Ltd; 2016:392-397.

2. Taneja DK. Demographic and Health Information of India. In: Banerjee B, ed. DK Taneja's Health Policies and Programmes in India. $15^{\text {th }}$ ed. New Delhi. Jaypee Brothers Medical Publishers (P) Ltd; 2017:55-57. 
3. Department of family welfare Ministry of Health \& family Welfare Government of India National Population Policy. 2000. Available at: fhttps://mohfw.gov.in/sites/default/files/2695375564 1410949469\%20\%281\%29.pdf

4. Taneja DK. National Population Policy 2000. In: Banerjee B, ed. DK Taneja's Health Policies and Programmes in India. $15^{\text {th }}$ ed. New Delhi. Jaypee Brothers Medical Publishers (P) Ltd; 2017:13-20.

5. Majhi AK. Family Planning and Contraception. New Delhi. Jaypee Brothers Medical Publishers (P) Ltd; 2018:687-690.

6. Gupta A, Verma A, Chauhan J. Evaluation of PPIUCD versus interval IUCD (380A) insertion in a teaching hospital of Western U.P. Int $\mathbf{J}$ Reprod Contracept Obstet Gynecol. 2013;2(2):204-8.

7. National Health Mission, Ministry of Health \& Family Welfare, Government of India. Available at: http://www.nhm.gov.in/nrhm-components/rmncha/family-planning/background.html.

8. Mishra S. Evaluation of safety, efficacy, and expulsion of post-placental and intra-cesarean insertion of intrauterine contraceptive devices (PPIUCD). J Obstet Gynecol India. 2014;64(5):33743.

9. Kant S, Archana S, Singh AK, Ahamed F, Haldar P. Acceptance rate, probability of follow-up, and expulsion of postpartum intrauterine contraceptive device offered at two primary health centers, North India. J Fam Med Prim Care. 2016;5(4):770.

10. Garg N, Grover S, Kaur B. Postpartum IUCD: its acceptance and complications. Int $\mathrm{J}$ Reprod Contracept Obstet Gynecol. 2017;6(7):2973-7.
11. Mishra S. Tale of the tails, the missing postpartum IUCD strings. Obstet Gynecol India. 2017;67(3):202-7.

12. Singal S, Bharti R, Dewan R. Clinical outcome of postplacental Copper $\mathrm{T}$ 380A insertion in women delivering by caesarean section. J Clinic Diagno Res: JCDR. 2014;8(9):OC01.

13. Kumar S, Sethi R, Balasubramaniam S, Charurat E, Lalchandani K, Semba R, et al. Women's experience with postpartum intrauterine contraceptive device use in India. Reprod Health. 2014;11(1):32.

14. Araujo VB, Ortiz L, Smith J. Postpartum IUD in Paraguay: a case series of 3000 cases. Contracept. 2012;86:173-86.

15. Nayak AK, Hota T. Hospital based-study regarding acceptance of PPIUCD as postpartum family planning method and its complications in a tertiary care hospital. Indian $\mathbf{J}$ Perinatol Reprod Biol. 2015;5(1):22-5.

16. Verma A, Sinha AR. Study of Postpartum IUCD Insertions in Tertiary Health care Centre in Bihar: Indian J Perinatol Reproduct Biol. 2014;4:8-10.

17. Kittur S, Kabadi YM. Enhancing contraceptive usage by post-placental intrauterine contraceptive devices (PPIUCD) insertion with evaluation of safety, efficacy, and expulsion. Int J Reprod Contracept Obstet Gynecol. 2016;1(1):26-32.

Cite this article as: Samanta S, Dutta S, Samanta S, Mullick A. A novel approach to meet the unmet need for family planning. Int J Reprod Contracept Obstet Gynecol 2019;8:169-73. 